\title{
HUMOUR AS A PROFESSIONALLY SIGNIFICANT COMPETENCE OF A TEACHER
}

\author{
Sviatlana Astapchuk ${ }^{1}$, Alena Barun $^{1}$, Sviatlana Vayavodzina $^{1}$, Natallia Dauhiala ${ }^{1}$, Dzmitry \\ Dauhiala $^{1}$, and Tatsiana Zhukava $^{1}$ \\ ${ }^{1}$ Polotsk State University, 211440 Novopolotsk, Belarus
}

\begin{abstract}
The article examines the issue of humour development as a professionally significant competence of a teacher. Conducted theoretical and empirical studies among students of secondary schools, tertiary education students, teachers and university professors have shown that students of secondary schools and university students, in comparison with school and university teachers, used humour more often in complicated situations. There were also differences in the choice of types of jokes by the respondents. The results of the study of humour reflects the ambiguous attitude towards humour that still exists in the teaching environment. The researchers have recorded the insufficient use of the possibilities of humour by teachers as an effective tool of pedagogical activity. The reason might be found in the current educational paradigm. A teacher is perceived as serious and even authoritarian. The development of this professionally significant quality is not given much attention in the process of training of future teachers. The use of humour as a pedagogical tool will help create conditions for the development of an individual style of professional activity, contribute to an increase in professional competence, pedagogical skills and will become one of the conditions for the effectiveness of solving various professional problems.
\end{abstract}

\section{Introduction}

Today education system needs teachers with a high level of personal development. In addition to highly developed communicative and intellectual qualities, creativity, empathy, a teacher should have a sense of humour. Humour in everyday life is an important personal quality; using humour makes it easier to cope with problems and difficulties that a person encounters in his/her life, including his/her professional activities.

\subsection{Materials and methods}

The prominent educators A.S. Makarenko, L.F. Spirin, K. D. Ushinsky in their works repeatedly noted the need for a sense of humour in teachers' activity. One of the most influential Soviet educator, V.A. Sukhomlinsky, when analyzing his experience in education, was one of the first to single out humour as one of the most powerful means of motivating and stimulating students' activities [1]. 
D. Korobkin indicated that shared laughter in the classroom was a powerful way to reinforce learning, it helped to make tasks less laborious and threatening [2], the teacher's use of humour had a positive effect on students' test scores [3]. Learning is more effective, interesting and useful if there is a place for a joke in the classroom, and the school team is more cohesive and friendly, it has a positive, cheerful atmosphere V. Ya. Propp [4]; R. R. Zhamilov [5]; O. A. Sergeeva [6] and others.

The use of humour in teaching has been studied in recent decades in pedagogy. Researchers unequivocally note that humour supports cognitive interest, evokes positive feelings and promotes more effective learning in students [7], educator humour has the potential to motivate learners [8]. Educators with a sense of humour are perceived as having a genuine concern for their students [9]. Effectiveness of using humour to increase selfmotivation, improve test performance, develop divergent thinking, help to illustrate and reinforce what is being taught, reinforce interest in learning, reduce anxiety and stress when dealing with difficult material, create positive social and emotional learning environment have been noted in other studies: R. A. Berk [10]; R. Deiter [11]; R. L. Garner [12], J.P. Powell\& LW. Andresen [13].

Humour is a powerful pedagogical tool, so its use needs certain requirements. They imply that a teacher must have a high level of communicative culture and culture of humour application in particular. Strategies for using humour must be planned well and teachers should avoid inappropriate uses of humour that degrade the dignity of a student, for example, mockery, sarcasm, teasing. A teacher can joke about individual actions of a student, but cannot ridicule student's personality, it is not appropriate to joke about physical or mental deficiency. J. Bryant and D. Zillmann pointed out that hostile types of humour could be effective as a deterrent to restore order in the classroom. When some students are ridiculed about being late, about their destructive behavior, missing assignments, it is a lesson to the rest of the class. Nevertheless, at the same time, it has a powerful suppressive effect [14]. L. Janes and J. Olson have also shown in their study that aggressive types of humour can have a negative impact on the emotional environment in the classroom [15]. J. Gorham and D. M. Christopher note that college teachers with aggressive types of humour are in most cases negatively assessed by students, it creates a general atmosphere of tension and anxiety, suppressing students' initiative and creativity [16].

The issue of using humour in education is in demand and it is relevant. However, for all the relevance of this issue, it is at the same time more complex than it might seem at first glance. With all the evidence of the effectiveness of the use of humour, there is not enough research on practical implementation and methodology of using humour in teaching.

Thus, the aim of our research is to study the use of humour as a pedagogical tool by teachers and students.

The research methods used in the study are systematization and analysis of scientific and methodical literature on the theory and practice of using humour in teaching, questionnaires for students and teachers.

\section{Results}

Humour is one of the most important components of educational process and upbringing. Humour is viewed as a form of play that comprises three components: cognitive (nonserious incongruity), emotional (mirth), and expressive (laughter). All of these elements have a social dimension [17]. From the point of view of pedagogy, humour is such a pedagogical tool, which is based on the awareness of communication participants of various types of inconsistencies (between the expected and what happened, between the visible and the real, etc.) associated with a comic effect, relieving psychological stress, contributing to creation of friendly relationship [18]. Educators who use humor are more 
positively assessed by students, use of humour is associated with students' perception that their teacher has "a positive attitude toward students", and "wants students to succeed" [9] and humour itself can improve learning [12].

Considering humour as a professionally significant personal quality of a teacher, it is necessary to determine its place in the structure of a teacher's personality. This issue has been widely studied. Moreover, although there are different approaches regarding the set of professionally significant personal qualities and their classification, they have a similar opinion on the significance of it. Researchers note that professionally significant personal qualities are a fundamental component of the teacher's personality and the most important factor in mastering the profession and teaching skills.

Most researchers, describing teachers' personality structure based on professionally significant personal qualities, do not always highlight humour and do not attach great importance to it. N. K. Shaidenko identifies dominant and peripheral professionally significant personal qualities. Dominant qualities are qualities without which a teacher cannot effectively carry out professional activities (for example, civic consciousness, love for children, sociability, optimism, empathy, etc.) and peripheral are those qualities of the teacher's personality that do not have a decisive influence on the productivity of his/her pedagogical activity, but contribute to its success. Peripheral qualities include, for example, friendliness, enthusiasm, seriousness, a sense of humour, charisma, initiative, curiosity.

V.A. Slastenin was the founder of the professiographic approach to the study of the teacher's personality. He devoted his research to the substantiation of the professiogram as a model of the teacher's personality. The pedagogical professiogram reflects invariant, idealized parameters of the personality and professional activity of a teacher. In his approach, the motivational-need, emotional-volitional, spiritual and cognitive-practical spheres of the personality, that is, both personality and teacher's activity, are almost equally reflected, but the emphasis is still placed on the teacher's personality. The presence of a sense of humour is preferable and belongs to the emotional-volitional sphere of an individual [19].

The structure of an ideal model of a teacher's personality, compiled by another teacher, namely L.F. Spirin, includes four blocks: personal traits of a teacher; professional and pedagogical knowledge; general pedagogical skills; general pedagogical abilities. L.F. Spirin does not exclude the possibility of a sense of humour as a significant emotional quality in the personality block of the teacher's personality structure. After all, a cheerful teacher is better than a gloomy one, because he/she has a joke, a successful aphorism, a smile, which creates a friendly emotional background in the classroom [20].

N.V. Kukharev and V.S. Reshetko believe that there are three groups of personal qualities of a teacher in the teachers' personality structure. The first group includes individual qualities that are difficult to develop or which cannot be developed at all; they are a sense of emotional sensitivity, delicacy, intuition, and a sense of humour. Another group of personal qualities of a teacher is based on the psychological mechanisms of interpersonal understanding and the third group consists of reflective level of pedagogical abilities.

Classifying and describing professionally significant personal qualities N.V. Kukharev and V.S. Reshetko indicate that the sense of humour belongs to the individual qualities that are difficult to develop, but it occupies a special place in pedagogical activity [21].

As we can see, the attitude towards a sense of humour is very ambiguous. Some researchers do not pay attention to it at all; others assign it a peripheral role, some of them single it out among the professionally significant personal qualities of a teacher, but at the same time argue that it is practically undeveloped. Each of the above-mentioned authors is right in their own way, but, in our opinion, humour should be given its well-deserved place in the training of teachers. 
We are sure that humour as a professionally significant competence of a teacher can contribute to the effective teaching and learning. O.A. Sergeeva describes the following functions of humour, they are informational (the teacher's humour shows his/her qualities and value relationships, and makes it possible to obtain information about students by their reaction to a joke); regulatory function (management of the pedagogical process and coordination of relations between a teacher and students); motivational (humour as a stimulus for self-development for both a teacher and students); finally, the emotional function (humour as a means of ensuring normal well-being in any situation, managing group mood, resolving conflict situations) [6].

According to N.E. Brazhenskaya, humour performs the most important functions in teacher's activities with students:

- it allows teachers to relieve physical and psychological stress of students, which makes it possible to activate students effectively, reveal their creative potential and show their personality from new sides;

- makes it possible to emphasize necessary items in the explanation of a new topic;

- helps to study personality traits of students;

- allows teachers to see positive and negative aspects of conflict situations and resolve them from a humanistic perspective;

- makes it possible, without specifying names, to delicately make comments about violations of discipline, being late for classes, untimely completion of tasks;

- promotes friendly relations in the group, as well as between a teacher and students;

- forms an idea of a teacher as a brilliant, creative and interesting person [22].

Thus, within the framework of the study of humour as one of the significant competencies of a teacher, humour is understood as a personal quality, expressed in an ability to original and non-standard approach to solving various problems, to treat certain life phenomena with a smile and irony. This is a quality that gives a person's activity and life a bright shade and it is related to creativity and talent. This understanding of humour indicates the need to develop this quality as a professionally important competence of a teacher.

Our research was carried out in two stages. At the first stage, a survey was conducted among schoolteachers and students of pedagogical faculties. The respondents were proposed to look through 150 personal qualities and they had to choose 30 , most significant from their point of view, out of the given qualities and distribute them into three groups of ten qualities each. The first group included qualities that characterized a teacher as a subject of pedagogical activity. The second one was dedicated to the qualities necessary for competent communication, interaction; the third - the qualities that allowed a teacher effectively influence the participants of educational process.

The data analysis showed that the teachers did not include a sense of humour in any of the proposed groups. They chose "high intelligence", "charisma", "authentity", "creativity" and other qualities, but no one chose humour as an important personal quality of a teacher. That could be explained by the system of requirements for an ideal image of a teacher, presented in classical pedagogy. An image of a teacher full of humour represents an inconsistency with the prevailing concept of a teacher as a "respected", "serious" and "strict" person, while a laughing and joking teacher does not correspond to this stereotype. The students, in turn, chose a sense of humour, but such choices were only 20 percent.

At the second stage of the study, three questionnaires were used, namely, "Human Responses to Various Types of Jokes (sense of homour)" H.Yu. Eysenck [23], "Psychological test for a sense of humour", by A.G. Barinova, "Humour and you", which were conducted with different groups of respondents [24].

20 students of the 3rd and 4th year of the Faculty of Humanities (pedagogical specialties) and 20 teachers of Polotsk State University took part in the first testing. 
While doing the first questionnaire SHRQ (H.Yu. Eysenck), the study group was asked to view 32 drawings in order of priority and evaluate them on a 5-point scale according to the following criteria: not at all funny - 1 point, a little funny - 2, rather funny - 3, very funny -4 , extremely funny -5 .

Based on the results of the study, the following table was compiled, reflecting the average score for each type of humour (see Table 1):

Table 1. Responses of Teachers and Students to Various Types of Jokes.

\begin{tabular}{|c|c|c|c|c|c|}
\hline & «Nonsense» & «Satire» & "Aggression” & "Sexual content" & Overall score \\
\hline Teachers & 14,2 & 18,9 & 17,1 & 16,6 & 16,7 \\
\hline Students & 26,9 & 22,7 & 26,6 & 34,3 & 27,6 \\
\hline
\end{tabular}

Analyzing the data we concluded that students were more inclined to find jokes funny and amusing than teachers did $(p>0,05)$. There were also differences in the "preferred humour profile". The students liked jokes with sexual content and jokes with "nonsense" more. Their average score for these types of humour is twice as high as that of teachers. The teachers, in turn, preferred cognitive humor, that is, "satire", as well as jokes containing direct aggression.

When conducting the second tool "Psychological test for a sense of humour" by A.G. Barinova, 25 fourth-year students of the Humanities Faculty and 25 teachers of the same faculty were interviewed. The questionnaire consisted of 10 multiple-choice questions (comic and serious). It should be noted that the teachers, even in a good mood, were too practical, sober in their judgments. At the same time, the students easily responded to the questions that were funny, but to a certain extent absurd. However, there were students in the group (11 percent of the respondents) with irrepressible humour. Their behavior may be misinterpreted, which, subsequently, may lead to undesirable conflict situations.

The third questionnaire was done by 20 teachers and 20 students of the 9th grade of secondary school No. 9 in Novopolotsk, as well as 20 teachers and 20 students of the Faculty of Humanities. They were offered the questionnaire by A.G. Barinova "Humour and You", it contained 10 multiple-choice questions.

We can see the results of the questionnaire "Humour and You"(by A.G. Barinova) in Fig. 1 .
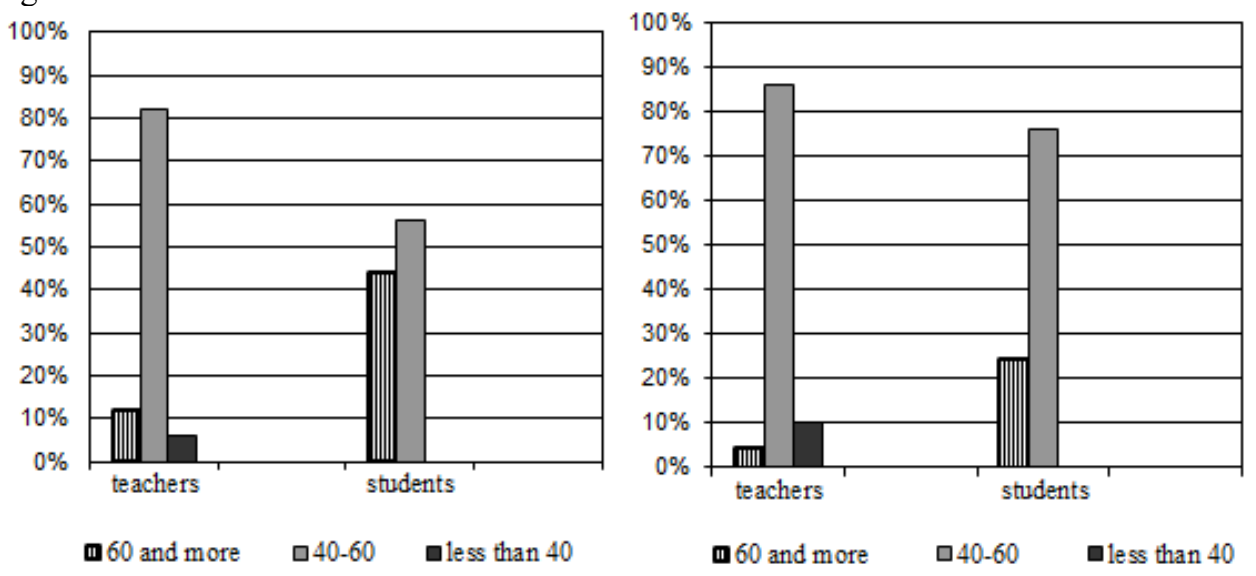

Fig. 1. The data of the questionnaire by A.G. Barinova "Humour and You".

The results obtained suggested that the students at school and university, had a more positive and cheerful attitude towards the surrounding reality than the schoolteachers and 
the university professors $(\mathrm{pS}>0,05)$. Students often laughed, joked and tried to perceive problems through the prism of humour. Teachers, perhaps due to their social status and age, had a pragmatic view of the world, a serious attitude to emerging difficulties, and, as a result, less often used humour in their work.

Thus, our research revealed that the students had a more developed sense of humour and were willing to demonstrate it. The teachers did not pay enough attention to humour, rarely or did not demonstrate it at all, and as a result, to a certain extent or even completely might have lost their sense of humour.

We can assume that one of the reasons of this is particular qualities of teaching activities. In most cases, a teacher has the right to perform certain functions: to control, manage, evaluate, and sometimes punish. These power functions form a behavior stereotype where there is no place for humour. An authoritarian teacher is sure that the use of a joke means a non-serious pedagogical position and can discredit him/her as a teacher. Such teachers do not assume that humour is not only a personal quality, but it can be a didactic and pedagogical tool. An appropriate joke, a funny poem or story, a witty proverb will always increase the effectiveness of students' cognitive activity.

A sense of humour is indeed difficult to develop. As students can easily respond to jokes, they are ready to use humour in communication and transfer it into future professional activities, some conditions for humour development and use in university professional training should be created, then this can increase the level of professional competence of future teachers.

\section{Conclusion}

In studying the possibility of using humour in education, we also note that, in principle, everyone has to some extent a sense of humour, and the more it is in demand, the more it develops and becomes more pronounced.

Considering that a sense of humour is a professionally significant quality of a teacher that contributes to the success of solving pedagogical problems, it is necessary to create certain conditions in pedagogical activity under which the sense of humour of teachers will improve and will not disappear with the years of teaching experience.

Possible conditions for maintaining and enhancing a sense of humour are:

- Focus on collaboration with students and other professionals in the process of teaching and upbringing;

- The dominance of the democratic style in pedagogical activity in order to avoid didacticism and callousness of teachers;

- Strengthening pedagogical orientation, including attitude towards a student as a subject of the pedagogical process;

- The formation of need to use interactive forms of conducting classes;

- Familiarization with techniques and requirements for using humour in teaching;

- creating a creative atmosphere in classroom.

A teacher who thinks about the problems of professional self-development and selfimprovement, in our opinion, should pay due attention to the use of humour in educational process. This will help to increase teacher's professional competence, pedagogical skills and will become one of the conditions for the effectiveness of solving professional problems.

\section{References}

1. V. A. Sukhomlinsky, Methods of educating a team (Moscow, Education, 1981) 
2. D. Korobkin, College Teaching, 36, 4 (1988)

3. A. Ziv, Journal of Experimental Education, 57 (1988)

4. V. Ya. Propp, Problems of comic and laughter (Moscow, Knowledge, 1989))

5. R.R. Zhamilov, Conflict experts club bulletin, 7 (1999)

6. O. A. Sergeeva, Preparing future teachers for the use of humor in teaching (Doctoral dissertation), Yaroslavl State Pedagogical University named after K.D. Ushinsky, Yaroslavl, (in Russ.) (1999).

7. M. B. Wanzer, A. B. Frymier, A. M. Wojtaszczyk, T. Smith, Communication Education, 55, 2 (2006)

8. A. K. Goodboy, M. Booth-Butterfield, San Bolkan, D. J. Griffin, Communication Quarterly, 63, 1 (2015).

9. J. H. Wilson, K. W. Taylor, Teaching of Psychology, 28 (2001)

10. R.A. Berk, Journal on Excellence in College Teaching, 7, 3 (1996).

11. R. Deiter, NACTA Journal (2000, June)

12. R. L. Garner, College Teaching, 54, 1 (2006)

13. J.P. Powell, LW. Andresen, Studies in Higher Education, 10 (1985)

14. J. Bryant, D. Zillmann, Using Humor to Promote Learning in the Classroom, Journal of Children in Contemporary Society, 49-78 (New York, Haworth Press, 1989).

15. L.M. Janes, J.M. Olson, Personality \& Social Psychology Bulletin, 26 (4) (2000).

16. . J. Gorham, D. M. Christophel, Communication Education, 39, 1 (1990).

17. R. A. Martin, The psychology of humor: An integrative approach (London, Ontario, Canada: Elsevier Academic Press, 2007)

18. S. M. Yusfin, Problems of Modern Education, 2 (2015)

19. V. A. Slastenin, Formation of the personality of a teacher of the Soviet school in the process of professional training (Moscow, Prosveshchenie [Education], 1976).

20. L.F.Spirin, Theory and Technology for Solving Pedagogical Problems (Moscow, Russian Pedagogical Agency, 1997)

21. N. V. Kukharev, V. S. Reshetko. Diagnostics of pedagogical skills and pedagogical creativity (Minsk, Adukatsya i vyhavanne, [Education and upbringing], 1996)

22. N.E. Brazhenskaya, Pedagogical journal, 6, 5 (2016)

23. G. Yu. Eysenck, G. Wilson, How to Measure Personality (Moscow, OOO KogitoCenter, 2000)

24. A.G. Barinova, Health, 4 (2004). 